\title{
Diversidades e violências no meio escolar: Experiências Docentes
}

Diversities and violence in the school environment: Teaching Experiences

Eliane Maura Littig Milhomem de Freitas ${ }^{1}$

Resumo: O presente artigo pretende discutir e elucidar situações que envolvem a diversidadee, portanto culmina com vários tipos de violências que ocorrem no meio escolar, às vezes simbólica, às vezes não. Essa violência se processa sob uma visão pedagógica equivocada e por meio um viés cultural e religioso que sustenta atitudes preconceituosas e discriminatórias no seio escolar. Para tanto serão destacados temas como direitos humanos, diversidade, currículo, violência, racismo velado que permeia a exclusão, educação especial, pobreza econômica e dificuldades de aprendizagem - fruto de uma condição social desfavorecida. De outro modo pretendem-se abordar as experiências também exitosas, que mediante a conscientização e conhecimento buscam a transformação, emancipação e protagonismo dos/as estudantes a fim de se sentirem pertencentes e com sua identidade reconhecida e valorizada. Essa condição poderá ser alcançada por meio de um currículo integrado e atento as questões explícitas ou não no cotidiano escolar.

Palav ras-chave: Direitos Humanos; Diversidades; Violência; Currículo; Experiências exitosas.

Artigo recebido em: 30 ago. 2018

Aprovado em: 30 ago. 2018

${ }^{1}$ Doutoranda em Ciências da Religião pela PUCSP - Pontifícia Universidade Católica de São Paulo. 
Abstract: This article aims to discuss and elucidate situations involving diversity and therefore culminates with various types of violence that occur in the school environment, sometimes symbolic, sometimes not. This violence takes place under a mistaken pedagogical vision and through a cultural and religious bias that sustains prejudiced and discriminatory attitudes in the school. In order to do so, themes such as human rights, diversity, curriculum, violence, veiled racism that permeates exclusion, special education, economic poverty and learning difficulties - the result of a disadvantaged social condition will be highlighted. Otherwise, we intend to approach the successful experiences that, through awareness and knowledge, seek the transformation, emancipation and protagonism of the students in order to feel their belonging and with their recognized and valued identity. This condition can be achieved through an integrated curriculum and attentive to explicit issues or not in everyday school life. Keywords:Human Rights; Diversity; Violence; Curriculum; Successful experiments.

\section{Introdução}

A escola é o espaço por excelência da aprendizagem, é importante que nela os indivíduos aprendam coisas importantes sobre vivências, diversidade, diferenças e etc. para que estes promovam a paz e vivenciem questões importantes como diálogo, tolerância dentre outros que possam ajuda-los para uma vida mais saudável e respeitosa.

Essas premissas abordadasdevem fazer parte do fazer pedagógico de todos/as os/as docentes que buscam com prioridade alcançar os princípios expressos tanto na Constituição Federal de 1988, como na Lei de Diretrizes e Bases da Educação Nacional (LDBEN) nº 9394/1996.

No entanto tal feito nem sempre toma as melhores feições no espaço pedagógico. Comumente os estudantes sofrem algum tipo de violência simbólica sobre as suas condições, quer seja religiosa, por sua origem racial, de orientação sexual, por educação especial, pobreza, dentre outras.

Se a escola pode ser um espaço de libertação e emancipação também pode ser de exclusão, invisibilização e toda a sorte de mecanismos que contribuem para a permanênciado status quo vigente.

De modo geral os/as agentes educativos/as não se dão conta que por meio do currículo escolar e das ten dências pedagógicas que privilegiam no dia a dia contribuem para a viabilização do aparelho ideológicodo Estado, quando por meio de sua ação educativa 
reproduzem situações e discursos que perpetuam a manutenção do status quo, a opressão e ainda a miséria social.

Esse artigo buscou selecionar alguns exemplos do cotidiano de professores/as e alunos/as que vivenciaram algum tipo de violência escolar seja pela invisibilização, negação de direitos e confirmação de situações que fortalecem o discurso opressor.

De outro modo experiências exitosas também serão apontadas a fim de descaracterizar somente os processos de denúncia, mas também esclarecer que há um movimento pedagógico atento, criterioso e cuidadoso para a escuta discente e ainda para libertação educativa e social. Essas experiências serão inseridas ao longo desse texto a fim de melhor elucidar situações que cotidianamente ocorrem nos espaços escolares.

Finalizando, o texto discute sobre o tema "Diversidade e escola: como articular um currículo integrador?” Pretende-se apontar algumas possibilidades de integração do currículo, assim como atentar para sua importância que por certo terá o alcance que se espera se houver também vontade política para melhorar as políticas públicas de acesso e inclusão e permanência na escola, uma rede de apoio e proteção por parte da sociedade, igreja e ministério público e formação de professores/as, cujos/as profissionais estão na ponta do processo e por sua ação educativa podem contribuir para melhoramento da educação, sobretudo sobre o tema que trata o presente texto.

\section{Direitos Humanos e Diversidade religiosa}

A declaração universal dos direitos humanos foi adotada e proclamada pela Assembleia Geral das Nações Unidas (resolução 217 A III) em 10 de dezembro 1948.

Por meio de tal texto busca-se uma compreensão mais ampla dos direitos e liberdades fundamentais dos indivíduos, assim como sua observância principalmente no que diz respeito à dignidade, valor da pessoa humana e na igualdade de direitos do homem e da mulher. É importante considerar que o Brasil é signatário de tal declaração.

No entanto, embora tal declaração seja bastante conhecida, inclusive no meio escolar Oliveira e Cecchetti sinalizam sobre os inúmeros conflitos, colonialismos, imperialismos, genocídios e, epistemicídios e culturicídios que vem estabelecendo-se nos mais 
diversos âmbitos e que dificulta a convivência com os diferentes e as diferenças ${ }^{2}$.

Colaborando com essa fala que busca denunciar os conflitos e tensões, Welter afirma que o mesmo ocorre na escola:

[...] De forma resumida, é possível
afirmar que a escola está permeada de
conflitos e contradições. Ao mesmo
tempo em que transmite e constrói
conhecimento, reproduz padrões sociais
dominantes, promove o encontro e
produz diferenças, distinções e
desigualdades nos/as e entre sujeitos
sociais, especialmente estudantes, mas
também entre profissionais da educação.
Ela se apresenta também como espaço
para experiências e relações
assimétricas, estímulo para valores
hegemônicos, repressões e opressões
sobre padrões não hegemônicos,
exercício de poder, conflitos e violências,
as quais nem sempre são penalizadas. As
violências vivenciadas no ambiente
escolar impõem aos estudantes graves
consequências pessoais, como danos
físicos, traumas, sentimentos de medo e
insegurança, além de sentimento de
insatisfação ${ }^{3}$.

No campo da religiosidade, a humanidade tem buscado respostas sobre a transcendência, assim como procura por meio dos mitos, ritos e símbolos traduzir seus sentimentos mais profundos que advém de suas crenças e fé. De modo que em linhas gerais todas as religiões tem algo em comum, isto é, a busca de uma relação com um mundo não físico e ainda a aproximação/comunhão com as pessoas.

Impressiona o fato de que no Brasil colônia, a supremacia da cultura e religiosidade europeia contribuiu em grande parte para

\footnotetext{
2 OLIVEIRA, Lílian Blanck de. CECCHETTI, Elcio. Aprendendo a conviver: diversidade religiosa e direitos humanos no cotidiano escolar. IN: CECCHETTI, Élcio e PIOVEZANA, Leonel (Orgs.). Interculturalidade e educação: saberes, práticas e desafios. Blumenau: Edifurb, 2015.

3 Welter, 2015, p. 217
} 
dominação de povos invisibilizados, tais como índios, considerados selvagens e os africanos, povos escravizados para servir ao colonizador e dominador.

No decorrer do desenvolvimento do país outras etnias foram se inserindo em Estado brasileiro, porém a europeia obteve a condição de uma civilização exclusivista. Sendo assim, muitas abordagens sejam no âmbito cultural e religioso predominou a visão eurocêntrica.

Em conformidade com a Cartilha da Diversidade Religiosa (2004), é importante ressaltar o quanto a comunidade humana é ricamente composta pela diversidade. Sendo assim, deve ser garantido aos indivíduos viver com dignidade, e serem respeitados em suas singularidades. Para tanto cabe a todos desfrutarem dos mesmos direitos, das mesmas oportunidades políticas, direitos educacionais, culturais, econômicos e sociais do país.

Segundo o texto citado, no campo da diversidade se insere a pluralidade que engloba as várias etnias, culturas, religiões, identidade de gênero, diversidade linguística que se consolida por meio do pressuposto de que todos são iguais, porém com suas diferenças.

Caberá a escola, as políticas públicas, a sociedade e a Igreja buscar um mundo com mais equidade, justiça social e valorização das diferenças. Tal exercício vem sendo protagonizado pelos agentes citados. No entanto há um bom percurso ainda pela frente; pois:

[...] os Direitos Humanos
somentematerializam através de
políticas públicas eficazes, capazes de
conferir sustentação ao pleno exercício
da cidadania, contemplando políticas e
ações que garantam o efetivo
cumprimento dos preceitos e normas
fundamentais e, principalmente,
resultem na redução as desigualdades
sociais4.

Desse modo convém ressaltar que a luta se dá cotidianamente, pois não adianta a conquista teórica, ela precisa acontecer de fato.Infelizmente muitos direitos nos são negados

4 BARUFFI, Helder. Direitos Humanos e Educação: Uma Aproximação Necessária. Revista Jurídica UNIGRAN. Dourados, MS | v. 8 | n. 15 | Jan./Jun. 2006. p.48. 
diariamente, e não há interesse em esclarecer ou orientar sobre o que os/as cidadãos/ãs têm direito.

No entanto "a educação compreendida como um compromisso com o ser humano, não só pode como deve desempenhar um papel fundamental na construção e no desenvolvimento de uma consciência cidadã, preocupada com a defesa dos Direitos Humanos e com a afirmação da Cidadania” (Baruffi, 2006, p.48).

Infere-se desse modo que o Direito a educação, que também faz parte dos princípios dos Direitos Humanos, poderá ser um elemento diferenciador na intervenção educativa.

Baruffi (2006) assinala que tanto o aluno como o professor deve exercer seu papel como divulgadores dos Direitos Humanos com vistas à consolidação das práticas sócio-políticas e democráticas.

\section{Apontamentos sobre o Currículo e sua materialização no espaço escolar}

Os estudos sobre currículo apontam informações importantes que se caracterizam pelos conceitos que as mesmas enfatizam e tal conceito por sua vez vem desenhando no universo das escolas um currículo que atende a sociedade conforme interesses políticos ou não dos atores e atrizes que se colocam nos espaços de disseminação dos saberes.

Desse modo é importante compreender que currículo não se constitui apenas em um rol de conteúdos que devem ser repassados aos/as alunos/as elencados em um livro didático e/ou em diretrizes curriculares.

A concepção de currículo inclui os aspectos básicos que envolvem os fundamentos filosóficos e sociopolíticos da educação, assim como os marcos teóricos e referenciais que se concretizam na escola. Estabelece os princípios de instrumentalização, teoria e prática, planejamento e ação.

O currículo é um dos locais privilegiados onde se entrecruzam saber e poder, representação e domínio, discurso e regulação. É também no currículo que se condensam relações de poder que são cruciais para o processo de formação de subjetividades sociais. Em suma, currículo, poder e identidades sociais estão 
mutuamente implicados. O currículo corporifica relações sociais 5 .

Conforme o autor citado, o currículo é um campo carregado de ideologia, cultura e relações de poder, que comumente está a serviço de um grupo dominante que tem como princípio sustentar o status quo.

O currículo é também identidade, desse modo os protagonistas da educação, ou seja, os/as alunos/as precisam se ver no currículo; pois currículo é lugar, espaço, território, é relação de poder, é trajetória, viagem, percurso, é autobiografia, nossa vida. O currículo é texto, discurso. No currículo se forja nossa identidade.

De conformidade com Jesus, tanto a teoria tradicional quanto a teoria críticaveem no currículo uma forma institucionalizada de transmitir a cultura de uma sociedade 6 . As Teorias tradicionais enfatizam o ensino aprendizagem-avaliação - metodologia- didática-organização planejamento - eficiência e objetivos; e as Teorias Críticas enfatizam a ideologia - reprodução cultural e social - poder- classe social capitalismo- relações sociais de produção - conscientização emancipação-currículo oculto e resistência.

As teorias pós-críticas vem ganhando destaque por buscar inserir elementos de emancipação tais como: identidade - alteridade - diferença subjetividade- significação e discurso - saber e poder - representação cultura - gênero - raça - etnia - sexualidade-multiculturalismo.

As teorias pós-críticas tem como premissa repensar o currículo e refletir sobre as questões que se apresentam sejam em âmbito so cial ou escolar.

De posse de tal conhecimento a escola e particularmente o/a docente deve revisar o seu currículo no que diz respeito à diversidade humana presente no universo escolar, pois o que se tem na escola é o/a aluno/a concreto/a.

Esse/a aluno/a ao adentrar o espaço escolar trás em sua bagagem, sua cultura, etnia, religiosidade, valores e outros que precisam no mínimo ser reconhecidos, tolerados e respeitados.

Comumente a escola preocupa-se com o currículo formal, isto é, o currículo estabelecido pelos sistemas de ensino, expresso em diretrizes curriculares, objetivos e conteúdos das áreas ou disciplinas de estudos.

Tal currículo enuncia o discurso da classe que está no poder, traduzido em disciplinas e programas, passado ao professor na forma de guias de ensino, programas e livros didáticos.

5 SILVA, Tomaz Tadeu da. Identidades terminais: as transformações na política da pedagogia e na pedagogia da política. Petrópolis: Vozes, 1996. p.23.

6 JESUS, Adriana Regina de. Currículo e Educação: Conceito e Questões no Contexto Educacional. Disponível em http://lagarto.ufs.br/uploads/content attach/path/11339/curriculo e ed ucacao o.pdf. Acesso em 20 de Dezembro de 2017. 
$\mathrm{Na}$ maioria das vezes esse currículo negligencia os saberes populares e a cultura do/a aluno/a, favorecendo uma pedagogia por muitas vezes excludente. De outro modo, o currículo real se materializa dentro da sala de aula com professores/as e alunos/as a cada dia em decorrência de um projeto político pedagógico e dos planos de ensino.

Em contrapartida se evidencia o Currículo Oculto, cujo termo é usado para denominar as influências que afetam a aprendizagem dos/as alunos/as e o trabalho do/a professor/a. Esse currículo representa tudo o que os/as discentes aprendem em meio às várias práticas: atitudes, comportamentos, gestos, percepções, que vigoram no meio social e escolar. Diz-se que está oculto porque ele não aparece no planejamento do professor.

Tal currículo tem sido bastante criticado por autores e pesquisadores; pois por meio de tal mecanismo contribui, de forma implícita para aprendizagens sociais relevantes ou não. O que se aprende no currículo oculto são fundamentalmente atitudes, comportamentos, valores e orientações que dentre outras dão o aparato didático para a formação do/a cidadão/ã.

\section{A violên cia simbólica e o discurso pedagógico que medeia à exclusão discente}

Moreira e Silva atestam que currículo oculto se evidencia nas influências que afetam a aprendizagem dos/as alunos/as e o trabalho dos/as professores/as; portanto representa tudo o que os/as discentes aprendem por meio das práticas, atitudes, comportamentos, gestos, percepções que se concretizam no currículo, porém não estão no planejamento escolar7.

Muitas vezes inconsciente e outras consciente a escola por meio de seus agentes educativos desenvolvem um currículo de exclusão, assumindo o papel de aparelho ideológico do Estado ${ }^{8}$.

Toma-se como exemplo a fala da professora Joana 9 quando afirma que alguns de seus alunos dificilmente concluirão o Ensino Fundamental, pois além da muita defasagem dos conteúdos, são pessoas com o destino traçado de exclusão e marginalidade social.

7 MOREIRA, Antônio Flávio Barbosa; SILVA, Tomaz Tadeu. (Org.). Currículo, cultura e sociedade. São Paulo: Cortez, 1997

8 Aparelho Ideológico do Estado. A elite burguesa reproduz sua lógica de dominação excludente e desigual. Eo faz principalmente através da escola, sem deix ar de lado, evidentemente, a igreja, a família, sindicatos, o direito e outros. Tal tema tem por base a obra Aparelhos Ideológicos de Estado deLouis Althusser.

9 Joana - nome fictício de uma professora para relatar fato ocorrido numa escola de um município da Grande Vitória - ES. 
Observa que tal discurso vem permeado de violência simbólica. $\mathrm{Na}$ perspectiva Bourdieusiana:

\begin{abstract}
[...] a violência simbólica se expressa na imposição legítima e dissimulada, com a interiorização da cultura dominante e há uma correlação entre as desigualdades sociais e escolares. As posições mais elevadas e prestigiadas dentro do sistema de ensino (definidas em termos de disciplinas, cursos, ramos do ensino, estabelecimentos) tendem a ser ocupadas pelos indivíduos pertencentes aos grupos socialmente dominantes ${ }^{10}$
\end{abstract}

Esse currículo desenvolvido pela professora citada não é um elemento neutro de transmissão de conhecimento social, mas está imbricado em relação de poder e das forças que atuam e se desenvolvem no seio educativo. Dessa feita a violência embutida é naturalizada favorecendo impulsos que se apresentam por meio de hábitos, palavras, costumes e tradições.

Em conversa sobre o currículo desenvolvido nas escolas, uma aluna relatou uma experiência que vivencia todos os dias, pois ao lado da sua casa existe uma escola de Educação Infantil. Segundo seu relato ela mesma não havia observado o tipo de música tocada nas entradas dos/as alunos/as, mas de vez em quando seu esposo que sai de casa mais cedo que ela observava que as crianças do CMEI (Centro Municipal de Educação Infantil) eram acolhidas com músicas de estilo Funk. Não acreditando no fato resolveu tirar a prova e foi surpreendida ao observar que nos dias em que fez a escuta da dinâmica de entrada dos/as alunos/as, o/a responsável por esse momento acolhe as criançascom estilo de músicas que considera inapropriado, dada a idade e ainda ao apelo sexual e de violência que a maioria das músicas apresenta.

$\mathrm{O}$ que responder a aluna que expôs essa denúncia? $\mathrm{O}$ currículo desenvolvido neste CMEI está servindo a quem? De que forma os gestores se apropriam desse conhecimento? O que seria mais pedagógico oferecer num ambiente infantil? Tais docentes estão envolvidos no processo de formação continuada? Entendem

10 SOUZA, Liliane Pereira de. A Violência Simbólica na Escola: Contribuições de Sociólogos Franceses ao Fenômeno da Violência Escolar Brasileira. Revista LABOR n ${ }^{0} 7$, v.1, 2012. 
que sustentam uma condição de exclusão e violência? Em que momento didático essas músicas são apropriadas?

Stoer e atesta que ações pedagógicas praticadas por diferentes classes ou grupos sociais comumente apoiam mesmo que indiretamente a ação pedagógica dominante; pois tal ação determina a organização e o funcionamento do mercado econômico e simbólico ${ }^{11}$.

Nesse sentido um fato curioso ocorreu com uma colega de trabalho, a quem chamarei de Marcia $^{12}$ que narrou sobre sua experiência em uma das escolas que leciona. A professora disse que há uma aluna que se veste de uma forma bastante diferente. $\mathrm{O}$ motivo dessa indumentária se deve ao fato de a avó ter todo um cuidado com a aluna e querer deixa-la muito bonita. A questão é que ainda pela manhã faça sol ou não ela está carregada de adereços; vestido de festa, calçado fechado, meia calça preta e outros adornos não apropriados tanto pela idade da criança como pelo fato que o meio escolar não os favorece. O que chamou muito a atenção da professora foi ouvir da parte pedagógica escolar em determinado momento que aquela menina era uma espécie de oferenda atribuindo a ela falas pejorativas em relação à religião de matriz africana.

$\mathrm{Na}$ escola acontecem muitas coisas inusitadas, e o que chama a atenção é que a mesma tem um estatuto, regras e organização. Possivelmente haveria outra forma de abordar a avó para uma explicação mais didática e menos vexatória.

A escola deve buscar questionar ideias, trocar experiências, chamar a família para conversar. Definir caminhos comuns, educando na prática da liberdade. No entanto na maioria das vezes não é isso que ocorre, é mais fácil deixar o problema acontecer sem buscar soluções para crescimento e autonomia em suas ações. Desse modo se corrobora para a alienação no seio da escola.

No dizer de Souza o Estado se constitui num elemento facilitador da classe dominante e por isso sua ação para buscar melhorias na escola pública em sua maioria está condicionada aos interesses da classe dominante ${ }^{13}$.

Outra questão bastante interessante diz respeito aos discursos docentes sobre a indisciplina de alunos/as, acompanhadas de falas de que eles/as não apresentam interesse em aprender. No entanto ao conversar com tais alunos/as compreende-se que esses/as desconhecem a linguagem

${ }^{11}$ STOER, S. R. A genética cultural da reprodução. Educação, Socie dade \& Culturas, n. ${ }^{\circ}$ 26, 2008, 85-90.

12 Márcia - nome fictício de uma professora para relatar fato ocorrido numa escolade um município da Grande Vitória - ES.

13 SOUZA, 2012. 
da escola; não entendem o que o/a professor/a quer de fato, assim como não conseguem alcançar o que a educação pode lhes oferecer em termos de melhoria de vida e condição social.

$\mathrm{Na}$ maioria das vezes o/a docente preocupado/a em corresponder ao currículo prescrito desenvolve seu trabalho pedagógico numa dinâmica conteudista muito alinhada a concepção bancária da educação discutida por Paulo Freire (1987). Tal educação compreende que quanto mais cheio estivero/a aluno/a melhor será o/a educador/a. Essa concepção também é qualificada como violência simbólica; pois desqualifica o/a aluno/a considerando-o como mero/a receptor/a do conhecimento.

$\mathrm{Na}$ visão "bancária" da educação, o "saber" é uma doação dos que se julgam sábios aos que julgam nada saber. Doação que se se funda numa das manifestações instrumentais da ideologia da opressão - aabsolutização da ignorância, que constitui o que chamamos de alienação da ignorância, segundo a qual esta se encontra sempre no outro. $\mathrm{O}$ educador, que aliena a ignorância, se mantém em posições fixas, invariáveis. Será sempre o que sabe, enquanto os educandos serão sempre os que não sabem. A rigidez destas posições nega a educação e o conhecimento como processos de busca $^{14}$.

É importante assinalar que Paulo Freire (2002) ao discursar sobre os saberes para ensinar atenta que a escola deve trabalhar com o/a educando/a, ensiná-lo a pensar, problematizar o seu mundo. Educar para a autonomia e buscar como prática a liberdade que nega o ser humano isolado, mas propõe uma educação autêntica inserida na realidade, que seja consciente e provoque a superação da condição de dominação.

De outro modo é importante assinalar que a escola nem sempre consegue responder as questões que se apresentam no seu contexto e cotidiano, tais como as defasagens de aprendizagem; aos problemas e distúrbios de aprendizagem, os problemas de ordem

14FREIRE, Paulo. Pedagogia do Oprimido. Rio de Janeiro: Paz e Terra, 1987 . p.58. 
afetiva dentre outros que precisam de ajuda de profissionais especializados.

Sendo assim é mister buscar a contrapartida do órgão central(secretarias de educação) das políticas públicas por meio dos/as legisladores/as; do poder judiciário e Conselho Tutelar.

A escola precisa formar uma rede apoio, proteção e ação concreta; pois só assim conseguirá com mais qualidade alcançar seus objetivos, sejam de ordem da aprendizagem ou de ordem disciplinar.

\section{Experiências exitosas: quando o conhecimento faz a diferença.}

Felício e Silva destacam que caberá ao/a docente em seu exercício profissional assumir a centralidade da proposta curricular, a qual deve convergir todas as ações realizadas ao nível das áreas disciplinares, tal trabalho deve ser desenvolvido "mediante a articulação vertical e horizontal dos conteúdos a serem trabalhados [...]que sejam capazes de articular e mobilizar os saberes das diferentes áreas disciplinares para responder aos desafios da realidade" 15 .

De conformidade com Jesus o currículo humanista desencadeia-se por meio da tendência denominada Escola Nova e que visa privilegiar a realidade dos/as alunos/as. O/a aluno/a é visto por sua identidade pessoal, por isso "o currículo tem a função de propiciar experiências gratificantes, de modo a desenvolver sua consciência para a libertação e auto realização" 16 .

Um exemplo exitoso é o da professora Mariana ${ }^{17}$ que ao desenvolver atividades de produção de histórias em sua sala de aula com alunos do $5^{\circ}$ ano do Ensino Fundamental, solicitou que cada aluno/a escrevessesua história a partir de suas experiências com uma mascote que foi adotada pela respectiva sala de aula. Ao final desse processo a professora providenciou a compilação dos textos produzidos pelos/as alunos/as, fotografou cada aluno/a e construiu um portfólio colorido que foi presenteado a todos/as discentes no final do período letivo.

\footnotetext{
15 FELÍCIO, Helena Maria dos Santos. SILVA, Carlos Manuel Ribeiro da Silva. Currículo e Formação de Professores: uma visão integrada da construção do conhecimento profissional. Rev. Diálogo Educ., Curitiba, v . 17 , n. 51, p. $147-166$, jan./mar. 2017 . p.154.

16 JESUS, 2017, p.264.

17 Mariana - nome fictício de uma professora para relatar fato ocorrido numa escola de um município da Grande Vitória - ES.
} 
Observa-se que a professora nessa atividade didática buscou por meio do currículo contribuição para uma atividade qualificadora, e que privilegiou o contexto dos/as educandos/as. E numa concepção progressista da educação teve como objetivo primordial a difusão do conteúdo, mas não de qualquer conteúdo e sim de um conteúdo contextualizado, isto é, as produções de seus/suas próprios/as alunos/as.

A autonomia docente que Paulo Freire testifica, diz respeito também a autonomia do educando, pois "saber que devo respeito à autonomia e à identidade do educando exige de mim uma prática em tudo coerente com este saber" 18 .

Em conversa com uma aluna, a quem chamarei de Sophia ${ }^{19}$, ouvi seu relato sobre o projeto que participou na escola em que estuda. Esse projeto se chama Mobiliza - ela o traduziu como "doação de tempo", mas que para quem participa, isto é, os/as alunos que apadrinham as crianças menores com condição social menos favorecida, oriundas de outra escola; não é apenas doação de tempo; mas sim compartilhamento de experiências; conhecer a realidade do outro, oferecer carinho e atenção. Os padrinhos e madrinhas (que são os/as alunos/as maiores) contam histórias, brincam, fazem musicalização e teatros por meio de oficinas. Ao final do dia presenteiam essas crianças com doces,chocolates e uma lembrancinha.

Quando relatou o fato, a Sophia registrou que ganhou muito mais do que doou. E, segundo ela, esse sentimento é extensivo a todos os/as seus/suas colegas; pois uma grande emoção envolve esses momentos que buscam conhecer e concretizar sentimentos, por meio de experiências vividas.

Nessa ação pedagógica, cabe destacar uma qualidade indispensável ao/a docente, como relata Freire, que diz respeito às suas relações com as liberdades que é a generosidade. "O clima de respeito que nasce de relações justas, sérias, humildes, generosas, em que a autoridade docente e as liberdades dos alunos se assumem eticamente, autentica o caráter formador do espaço pedagógico" ${ }^{20}$.

É imperioso registrar que a generosidade vem carregada de sentimentos auspiciosos, e o que faz o/a educador/a é o fato de ser humano. "Me movo como educador porque, primeiro, me movo como gente" 21 .

\footnotetext{
18 FREIRE, 2002 , p.67.

19 Sophia - nome fictício de uma aluna para relatar fato ocorrido numa escola do município da Grande Vitória - ES.

20 FREIRE, 2002, p.103.

${ }^{21}$ FREIRE, 2002, p.106.
} 


\section{Diversidade e escola: como articular um currículo integrador?}

Conforme Santos, no contexto escolar estão presentes muitas diversidades. Algumas muito comuns e presentes em centros urbanos, tais como a diversidade religiosa; a diversidade de gênero; alunos com necessidades educacionais especiais; diversidade étnicoracial, e cultura afro-brasileira e africana; diversidade socioeconômica e cultural.

Outras diversidades ocorrem em locais mais pontuais comoà diversidade do campo e a indígena.

A autora citada anteriormente destaca sobre elementos muito importantes e norteadores para uma educação inclusiva que são a preservação da dignidade humana; a busca de identidade e o exercício de cidadania.

Nesse sentido as diversidades apresentadas destacam-se como desafios docentes; pois a garantia do exercício da liberdade e do respeito é um dos valores cidadãos mais importante.

Em relação à diversidade religiosa Silva (2008) atesta sobre a valorização do patrimônio histórico, do entendimento e compreensão do fenômeno religioso; da não catequese, mas do princípio da tolerância e alteridade do outro e ainda das manifestações religiosas, do equilíbrio e da imparcialidade.

Assim também a discussão sobre a diversidade de gênero é muito urgente, para garantir o conhecimento e a disseminação da ignorância. A exclusão da mulher sempre foi marcada seja na sociedade, no mercado de trabalho, nas relações conjugais e etc. Por outro lado, além de discutir sobre o masculino e o feminino é importante considerar outras construções da sexualidade humana, tais comoa discriminação aos homossexuais, transexuais dentre outros que vem sofrendo estigmas, estereótipos e outros tipos de violência que tem levado muitos seres humanos a morte pelo fato de serem diferentes.

A diversidade que trata dos/as alunos/as com necessidades educacionais especiais galgou o direito também na esfera educativa; pois a Constituição assevera que o direito a educação é para todos e todas. No entanto há ainda uma grande separação, isto é, uma lacuna que precisa ser mais bem entendida. Muitas vezes a inclusão se configura numa exclusão dentro da própria escola; assim como paira um desconhecimento sobre as adaptações curriculares; a avaliação do trabalho pedagógico; a intervenção psicopedagógica; os 
recursos materiais e o melhor entendimento sobre uma nova concepção da educação especial.

A diversidade étnico-racial principalmente a cultura afrobrasileira e africana ainda hoje sofrem preconceitos marcantes, sejam pelas falas ofensivas ou pelo racismo velado. A Lei 10.639/03 busca refletir sobre tais diferenças e discriminações, valorizando a cultura, a história, a identidade, e desse modo combater o racismo e a discriminação. A marginalização cultural, o racismo, preconceitos, baixa autoestima, contribuem em grande parte para a evasão e repetência escolar, dentre outros fatores desfavoráveis à cultura afro-brasileira e africana.

Outro fator desfavorável presente no campo educacional diz respeito à diversidade socioeconômica e cultural, que contribui em grande parte para a defasagem de aprendizagem; cujos filhos/as são de pais/mães boias frias, trabalhos com menor remuneração e por isso muitas vezes são desprovidos de todo tipo de assistência seja de alimentação, saúde, segurança e etc. Essa condição social trás consequências para o desempenho escolar e favorece uma condição social bem vista pela classe dominante e, portanto assim como as demais diversidades apontadas se constituiem campo de violência social.

A escola na sua missão educativa deve refletir com seus/suas alunos/as sobre essas diferenças, abrir para o diálogo, promover o respeito, garantindo o princípio da igualdade na diferença; pois nenhuma razão pode justificar na exclusão de pessoas em qualquer instância que seja.

Dessa feita o grande desafio da escola, sobretudo a escola pública diz respeito à inserção desses/as alunos/as com suas diversidades no âmbito escolar, buscando garantir o acesso e sua permanência na escola, e ainda garantir o acesso ao conhecimento e o sucesso na aprendizagem; pois por meio da escolarização se pensa na transformação social.

No entanto, comumente a escola e seus agentes educativos desenvolvem seu trabalho pedagógico tendo como base o currículo formal; mas quanto mais se buscar integrar o currículo, mais se evidenciará as questões prementes do currículo oculto, contribuindo para a metamorfose educativa.

Davini sustenta que o currículo integrado pode ser definido como um plano pedagógico e sua correspondente organização 
institucional que articula dinamicamente trabalho eensino, prática e teoria, ensino e comunidade ${ }^{22}$.

No dizer da autora, este currículo integrado é uma opção educativa que permite uma efetiva integração entre ensino e prática profissional; a real integração entre prática e teoria e o imediato teste da prática; um avanço na construção de teorias a partir do anterior; a busca de soluções específicas e originais para diferentes situações; a integração ensino-trabalho-comunidade, implicando uma imediata contribuição para esta última; a integração professoraluno na investigação e busca de esclarecimentos e propostas; a adaptação a cada realidade local e aos padrões culturais próprios de uma determinada estrutura social. Ela também assinala que o currículo deve sempre ser flexível, adaptável às diversas situações, passível de avaliação e aprimoramento.

Em se tratando das questões da diversidade é importante considerar que a escola tem o/a aluno/a real. Sendo assim caberá à própria possibilitar ao/a aluno/a ver-se nesse campo acadêmico.

Para tanto a diversidade deve ser valorizada, estudada e também problematizada, ou seja, é importante que se busque entender as razões que fizeram a escola negligenciar os saberes que advêm das culturas diferentes, compreender os conflitos e suas consequências, proporcionar o diálogo, a tolerância e ainda $\mathrm{o}$ conhecimento.

Em se tratando da diversidade religiosa, étnico racial e sexual, tem-se observado muita intolerância. Essa intolerância se manifesta muitas vezes pelo preconceito, em casos mais graves pela discriminação, e ainda com violências, guerras e até mortes.

Sendo assim, podemos questionar sobre o que move os indivíduos ao ponto de os mesmos realizarem as violências apontadas acima? $O$ que fomenta essa intolerância? Porque as pessoas odeiam sem conhecer? $O$ que há de anormal em ser diferente?

Para responder a tais questionamentos é imperioso citar o pensamento de Mandela, um dos maiores líderes em relação aos direitos humanos que assim afirma: "ninguém nasce odiando outra pessoa pela cor de sua pele, por sua origem ou ainda por sua religião. Para odiar, as pessoas precisam aprender, e, se podem aprender a odiar, podem ser ensinadas a amar" 23 . ado 0.pdf. Acesso em 26 de Dezembro de 2017. 
Dessa feita considera-se como prioritário uma conscientização na formação cidadã. É no universo da escola, onde os saberes, conhecimentos e as culturas são privilegiados.

$\mathrm{Na}$ escola se deve aprender sobre o outro e assim buscar o entendimento preconizado nos pilares da Educação, apresentados no Relatório para a UNESCO, por Delors ${ }^{24}$.

Dentre tais conhecimentos aponta-se o aprender a conhecer, aprender a ser, aprender a fazer e aprender a conviver. Em tais pilares destacam-se temas/valores/aprendizagens fundamentais para uma escola que se vê como aprendiz. Dentre esses podemos destacar ações como compreender, construir, desenvolver acuriosidade, buscar a autonomia, aprender a pensar, trabalhar em equipe, resolver os conflitos, aprender a viver com o outro, compreender o outro, e a interdependência.

Toma-se como algo muito valoroso discutir sobre a importância da não violência, envolver-se em projetos comuns e de interesse da coletividade ou de minorias, ser colaborativo, desenvolver a responsabilidade pessoal, buscar a espiritualidade, sensibilizar-se com o outro, buscar a criatividade.

Como sujeitos ativos desenvolver o sentido ético e estético, favorecer a criticidade outras virtudes que ajudarão a formar os/as alunos para um mundo mais plural e com diversidades marcantes, porém não negligenciando as particularidades e identidades.

A diversidade é algo bastante presente em nosso mundo atual e, nos dias de hoje, precisa ser pedagogicamente mais valorizado. Conviver com a diferença ajuda os indivíduos a crescerem e se desenvolverem como cidadãos/ã.

Contudo observa-se que a escola precisa se exercitar mais e sair do papel. Deve mostrar-se na sociedade e provocar também o seu envolvimento nesse exercício.

\section{Conclusão}

O presente texto buscou discorrer sobre o cotidiano da escola no que diz respeito a diversidades e violências.

Educar conforme ensina o mestre Paulo Freire requer muitas habilidades e nem sempre seus agentes desenvolvem o aprendizado necessário para este trabalho, como também nem sempre estão

24 DELORS, Jacques. Educação: Um tesouro a descobrir. São Paulo: Cortez; Brasília. DF: MEC: UNESCO, 1999. 
disponíveis para o mesmo. No entanto, há exemplos muito exitosos, onde se pode observar não só competência, como também vocação para o exercício do magistério. Pois essa ação não é neutra e sim carregada de ideologias e compromisso social e político.

De outro modo é importante registrar que para ocorrer um bom desenvolvimento da educação é necessário à criação de uma rede de cuidados e proteção. A vontade deve ser do poder público por meio de seus agentes em todas as instâncias, assim como da sociedade e da igreja que devem abraçar a causa educativa junto com a escola.

A escola, sobretudo a pública recebe indivíduos que trazem consigo uma diversidade muito ampla e como tal devem ser acolhidos, respeitados e inseridos no universo da escola usufruindo todos os seus direitos.

Destaca-se como ponto exitoso um currículo integrador que reconheça as diferenças, que se abra para o novo, que busque novas metodologias, que esteja aberto a diversidades existentes e que a escola não se omite de seu papel educativo na perspectiva dos Direitos Humanos.

\section{Referências}

BARUFFI, Helder. Direitos Humanos e Educação: Uma Aproximação Necessária. Revista Jurídica UNIGRAN. Dourados, MS | v. 8 | n. 15 | Jan./Jun. 2006.

DAVINI, Maria Cristina.Disponível em http://lagarto.ufs.br/uploads/content attach/path/11340/curriculo integrado o.pdf. Acesso em 26 de Dezembro de 2017.

Diversidade Religiosa e Direitos Humanos - Cartilha da Diversidade. Secretaria Especial dos Direitos Humanos, 2004.

Declaração Universal dos Direitos Humanos. Disponível https://www.unicef.org/brazil/pt/resources 10133.htm. Acesso em 20 de Dezembro de 2017.

DELORS, Jacques. Educação: Um tesouro a descobrir. São Paulo: Cortez; Brasília. DF: MEC: UNESCO, 1999. 
FELÍCIO, Helena Maria dos Santos. SILVA, Carlos Manuel Ribeiro da Silva. Currículo e Formação de Professores: uma visão integrada da construção do conhecimento profissional. Rev. Diálogo Educ., Curitiba, v. 17, n. 51, p. 147-166, jan./mar. 2017.

FREI RE, Paulo. Pedagogia do Oprimido. Rio de Janeiro: Paz e Terra, 1987.

- Pedagogia da Autonomia: Saberes Necessários a Prática Educativa. Rio de Janeiro: Editora Paz e Terra, 2002.

JESUS, Adriana Regina de. Currículo e Educação: Conceito e Questões no Contexto Educacional. Disponível em http://lagarto.ufs.br/uploads/content attach/path/11339/curriculo e educacao o.pdf . Acesso em 20 de Dezembro de 2017.

MOREIRA, Antônio Flávio Barbosa; SILVA, Tomaz Tadeu. (Org.). Currículo, cultura e sociedade. São Paulo: Cortez, 1997.

OLIVEIRA, Lílian Blanck de. CECCHETTI, Elcio. Aprendendo a conviver: diversidade religiosa e direitos humanos no cotidiano escolar. IN: CECCHETTI, Élcio e PIOVEZANA, Leonel (Orgs.). Interculturalidade e educação: saberes, práticas e desafios. Blumenau: Edifurb, 2015.

SILVA, Tomaz Tadeu da. Identidades terminais: as transformações na política da pedagogia e na pedagogia da política. Petrópolis: Vozes, 1996.

SOUZA,Liliane Pereira de. A Violência Simbólica na Escola: Contribuições de Sociólogos Franceses ao Fenômeno da Violência Escolar Brasileira. Revista LABOR n ${ }^{0} 7$, v.1, 2012.

STOER, S. R. A genética cultural da reprodução. Educação, Sociedade \& Culturas, $n .^{\circ}$ 26, 2008, 85-90. 